\title{
O ativismo cultural e a imaginação da fronteira Brasil-Uruguai
}

\author{
Cultural activism and the imagination of the border between \\ Brazil and Uruguay
}

\author{
El activismo cultural y la imaginación de la frontera \\ Brasil-Uruguay
}

Felipe José Comunello*

\begin{abstract}
Resumo: Este artigo objetiva analisar os modos pelos quais determinados agentes e movimentos políticos que atuam em defesa de políticas culturais imaginam a área de fronteira entre Brasil e Uruguai como um espaço cultural comum. A pesquisa de campo na qual se baseia essa análise foi realizada com militantes da cultura (assim autodenominados) e distintos agentes culturais que vivem ou atuam nesta área de fronteira, dentre os quais se encontram músicos, poetas, realizadores de cinema, documentaristas, produtores, entre outros. Tanto uns quanto outros se tornam inseparáveis quando se observa uma tendência de simultaneidade entre o seu ativismo cultural e a sua afirmação profissional. Analisam-se tais modos específicos de atuação em defesa de políticas culturais voltadas para a área de fronteira. Pretende-se discutir como a fronteira enquanto um símbolo é mobilizada na atuação política e profissional destes agentes e quais seus reflexos nas dinâmicas sociais e políticas locais e regionais.
\end{abstract}

Palavras-chave: Ativismo. Políticas culturais. Imaginação. Fronteira. Profissão.

\begin{abstract}
This article aims to analyze the ways in which certain officers and political movements acting in defense of cultural policies imagine the border area between Brazil and Uruguay as a common cultural space. The fieldwork on which this analysis is based was carried out with agents who called themselves militants of the culture and different cultural agents who live or work in this frontier area, among which are musicians, poets, filmmakers, documentarists, media producers, among others. Officers and political movements are indistinguishable when one observes a tendency of simultaneity between the cultural activism and the professional affirmation. We analyze these specific ways of acting in defense of cultural policies aimed at the frontier area. It is intended to discuss how the border as a symbol is mobilized in political and professional activities of these agents and what are its effects on social and local and regional political dynamics.
\end{abstract}

Keywords: Activism. Cultural policies. Imagination. Border. Profession.

\footnotetext{
* Universidade Federal do Rio Grande do Sul em Tramandaí, RS, Brasil. autor.dados_biográficos
}

Civitas, Porto Alegre, v. 18, n. 2, p. 303-318, maio-ago. 2018 
Resumen: Este artículo tiene como objetivo analizar los modos por los cuales determinados agentes y movimientos políticos que actúan en defensa de políticas culturales imaginan el área de frontera entre Brasil y Uruguay como un espacio cultural común. La investigación de campo en la que se basa este análisis fue realizada con agentes que se autodenominan militantes de la cultura y distintos agentes culturales que viven o actúan en este área de frontera, entre los que se encuentran músicos, poetas, realizadores de cine, documentalistas, productores, entre otros. Se observa una tendencia de simultaneidad entre activismo cultural y afirmación profesional de todos estos agentes. Se analizan modos específicos de actuación en defensa de políticas culturales dirigidas al área de frontera. Se busca discutir cómo la frontera es un símbolo movilizado en la actuación política y profesional de estos agentes y cómo se imbrica en las dinámicas sociales y políticas locales y regionales.

Palabras clave: Activismo. Políticas culturales. Imaginación. Frontera. Profesión.

\section{Introdução}

A fronteira entre Brasil e Uruguai tem sido alvo de iniciativas de desenvolvimento e cooperação internacional, com destaque para a Agenda Binacional de Cooperação e Desenvolvimento Fronteiriço (2002). ${ }^{1}$ Esta e outras iniciativas que se seguiram também foram protagonizadas por diversos atores sociais. Este artigo aborda a mobilização de ativistas políticos da cultura em algumas delas, que estão abaixo descritas. Eles protagonizaram mobilizações que estiveram associadas à incorporação de noções tais como "integração cultural", "fronteiras culturais" ou "cultura de fronteira" em acordos e eventos binacionais.

Esses ativistas podem ser divididos em dois grupos. O primeiro conformado por aqueles que se autodenominavam militantes da cultura de fronteira e atuavam no governo federal no segundo governo de Luiz Inácio Lula da Silva (2007-2010) ou no governo estadual de Tarso Genro (2011-2014). ${ }^{2}$ E o segundo, por distintos agentes culturais que vivem ou atuam na região fronteiriça, dentre os quais se encontram músicos, poetas, realizadores de cinema, documentaristas, produtores e militantes da cultura. Um, conformado por quem se autoidentifica principalmente desde sua atuação política, ativista, e outro, pela sua atuação no âmbito estético, o artista. No entanto,

\footnotetext{
${ }^{1}$ Essa Agenda pôs em prática o Acordo de Permissão de Residência, Estudo e Trabalho para Fronteiriços; o Comitê Binacional de Intendentes e Prefeitos de Fronteira em 2004; A Comissão Bilateral de Planejamento Estratégico e Integração Produtiva, em 2010.

${ }^{2}$ O segundo governo Lula é um marco importante, pois em 2009 ocorreu a declaração de Santana do Livramento, cidade símbolo da integração brasileira com os países membros do Mercosul. Nesse mesmo ano ocorreu a aprovação de normas para Pontos de Cultura pelo Parlamento do Mercosul. Em 2010, o presidente Luís Inácio Lula da Silva se encontrou com presidente uruguaio José Pepe Mujica na fronteira Rivera-Santana do Livramento.
} 
concretamente, observou-se a simultaneidade entre o ativismo cultural e a afirmação profissional dos agentes. De acordo com Irisarri (2015), ao longo dos primeiros quinze anos deste século as concepções de cultura têm sido multiplicadas e modificadas na produção cultural no Brasil, passando também a incluir o emprego, o engajamento político, a criação de modos de vida e de carreiras.

$\mathrm{Na}$ fronteira entre Brasil e Uruguai, esse fenômeno - a conformação de grupos ou movimentos culturais que combinam práticas políticas com culturais - também é perceptível. Destaca-se a organização do Calendário da Integração Cultural Brasil-Uruguai (2014) e o ato público Diálogo de Fronteira (2015) com a participação dos Ministros da Cultura do Brasil e do Uruguai na cidade de Jaguarão. $\mathrm{O}$ ativismo político dos organizadores buscava, no primeiro caso, a participação de artistas e trabalhadores de ambos os países em um calendário de eventos comuns e, no segundo, um plano de cultura para as fronteiras e editais específicos do Ministério da Cultura do Brasil.

Estes ativistas mobilizam valores culturais enraizados e acabam dando um sentido particular para o seu compromisso profissional, prefigurando assim a área de fronteira como um espaço cultural comum. Dessa maneira, ainda que o simbolismo da fronteira seja mais forte à distância, ele também existe na fronteira (Heyman e Symons, 2012).

O objetivo deste artigo é analisar como a fronteira entre Brasil e Uruguai é moralmente imaginada como um espaço comum por esses ativistas, como transcorre sua atuação política e profissional e de que forma se constituem. Primeiramente discutem-se abordagens antropológicas sobre fronteira, destacando-se o enfoque na imaginação moral. Em seguida, parte-se para a descrição e análise da participação dos ativistas nas iniciativas acima evocadas.

\section{Que fronteira?}

Entre ativistas e produtores culturais que atuam na fronteira do Brasil com o Uruguai, com frequência fronteira é sinônimo de Faixa de Fronteira do lado brasileiro (150 km de largura paralelos à linha terrestre divisória do território nacional, considerada Área de Segurança Nacional pela Lei no 6.634, de 2 de maio de 1979), sobretudo quando se faz necessária uma referência legal para eventos culturais ou políticas governamentais. Também é comum a fronteira ser considerada como equivalente às chamadas cidades gêmeas (Santana do Livramento-Rivera, Quaraí-Artigas, entre outras). Cidades como Pelotas, que está no limite da Faixa de Fronteira, ou Porto Alegre, que se encontra distante da referida faixa, eventualmente também são consideradas fronteira devido à convivência com uruguaios que vivem no país ou ao histórico de confrontos e interações na ocupação deste território. Nessa perspectiva, a fronteira pode ser 
evocada para explicar características dos habitantes do estado do Rio Grande do Sul que, pela proximidade linguística ou geográfica com o Uruguai, no limite, seria um estado "de fronteira".

Para a compreensão da imaginação moral da fronteira, cabe enfatizar as definições desenvolvidas no âmbito da antropologia. Segundo Faulhaber (2001), a abordagem antropológica do conceito fronteira leva em consideração as implicações simbólicas, identitárias e culturais:

A acepção antropológica da fronteira como um "fato social total" considera, sobretudo, o terreno imaginário no qual se constitui. As representações sobre limites e a incorporação de aspectos considerados ainda não plenamente estruturados por forças impulsionadas a partir de um "centro" propulsor incluem-se nessa definição como faces de uma mesma moeda (Faulhaber, 2001, p. 108).

Nesse sentido, com fronteira trata-se de uma área espacial e simbólica mais ou menos definida, que varia de acordo com os contextos. Dessa maneira, por exemplo, se pode explicar que, em determinadas ocasiões, a fronteira seja equivalente a cidades gêmeas, em outras, à Faixa de Fronteira e assim por diante. Portanto, é um conceito que incorpora os limites territoriais, neste caso entre os países de Brasil e Uruguai, mas também os diversos aspectos que a constituem e não são determinados a partir de centros propulsores, como, por exemplo, Brasília ou Montevidéu. Cabe assinalar que, nessa abordagem, não se considera que identidades são constituídas opondo-se em círculos concêntricos a partir dos "centros". Segundo Faulhaber (2001, p. 108), "antes de círculos, observam-se segmentos e uma rede de relações de oposição - manifesta ou virtual - em campos de força. Essas relações são baseadas na percepção da diferença entre categorias sociais".

Este tipo de abordagem é muito próximo do que se encontra em pesquisa realizada nas cidades de Rivera e Santana do Livramento. Segundo Sánchez (2002), é comum os habitantes dessas cidades se referirem à "linha" para indicar o limite geográfico entre Brasil e Uruguai. Muitas dessas pessoas são riverenses ou santanenses ou ambos (doble chapas) ou simplesmente "fronteiriços". Em Santana do Livramento ou Rivera, de fato, quando se está na linha entre um país e outro as mudanças são quase imperceptíveis. De modo geral, Sánchez (2002) demonstra como a "linha" que separa os dois países converte-se em um lugar que os transforma em "cá" e "lá" e "este lado" e "outro lado" na vida cotidiana. Algo semelhante também ocorre em outras partes do Brasil onde populações vivem nos limites nacionais, como é o caso 
da chamada Tríplice Fronteira entre Brasil, Argentina e Paraguai, que tem sido objeto de farta pesquisa (Sprandel, 2006; Albuquerque, 2009; Rabossi, 2011).

Como nota Rabossi (2011), o que faz esses lugares deixarem de ser apenas pontos cartográficos para se tornarem regiões ou aéreas de fronteira é a ocupação humana. Rabossi também lembra que, no caso da América Latina, a presença de população é decorrente dos próprios limites internacionais, pois as cidades foram fundadas em um contexto mais amplo de ocupações e conexões. É importante não perder de vista esse contexto mais amplo, face a dois tipos de essencialismos que se sustentam nas metáforas de união e, em particular, de travessia, os quais ganharam "widespread acceptance, both academically and politically, in places as distant as the U.S.-Mexico border and different Mercosur frontiers" (Grimson e Vila, 2002, p. 69).

Grimson (2012) cunha o termo borderization para se referir ao processo histórico em que os elementos que compõem a fronteira são formados, pela interação do poder central com as populações locais, e também, desde uma perspectiva sociocultural, no qual a fronteira nunca é um fato, mas permanece sempre instável e inacabada. Para ele, esse processo na região em estudo teve primeiro um estágio territorial que remonta ao período que vai da assinatura do Tratado de Tordesilhas em 1494 até a consolidação dos estados-nação no início do século 20, depois, um estágio de povoamento das fronteiras a partir dos anos 1930 e outro estágio mais recente de integração regional a partir de meados dos anos 1980, com a criação do Mercosul e a globalização nos anos 1990. Segundo Grimson (2012, p. 197):

Today states are focused not on territory or populations but rather on cross-border trade. Interstate struggle can therefore manifest itself in strategies to maximize a state's exporting capacity while limiting that of its neighbors. This can affect not only cross-border movements, but also the sense in which the border is viewed.

Diante disso, pode-se observar que a Agenda Binacional de Cooperação e Desenvolvimento Fronteiriço aprovada por Brasil e Uruguai em 2002 assim como as iniciativas que se seguiram estão em alguma medida na contracorrente desse processo histórico. Frente ao mencionado anteriormente (ver notas 1 e 2), essa Agenda e demais iniciativas buscam pautar temas relacionados à integração regional e fronteiras, sobretudo, aqueles voltados à ampliação do sentido que é dado pelos estados nacionais para a fronteira. O início da pesquisa apresentada neste artigo deu-se com a observação das maneiras como em distintas situações a fronteira era constantemente tematizada e vivenciada, em especial, em articulações relacionadas a políticas culturais. 
Observou-se a promoção da diversidade cultural na fronteira (Faixa de Fronteira, para efeitos de eventos e políticas correspondentes) por agentes sociais que têm distintas formas de vivência nela. Os contornos dessa promoção, quando tomavam uma tendência de crítica, afirmavam um descontentamento com as decisões sobre leis, políticas e programas tomadas nos centros de decisão distantes das realidades da fronteira. Realidade para a qual soluções locais estariam sendo buscadas, enquanto os conflitos seriam gerados por decisões nos âmbitos nacionais. Seriam reações à negligência dos governos nacionais de Brasil e Uruguai, os quais intervêm na fronteira, muitas vezes sob a justificativa da integração regional do Cone Sul da América do Sul, por meio de diferentes acordos, políticas, eventos e programas.

Essas questões estão relacionadas a um debate mais geral, identificado por pesquisadores em outros contextos. Trata-se de outra vertente da abordagem antropológica sobre o conceito de fronteira. Heyman e Symons (2012), a partir de pesquisas sobre a fronteira entre México e Estados Unidos, lembram que há um paradoxo no coração das democracias liberais, entre reivindicação de autodeterminação soberana e princípios universais de direitos humanos. Para melhor compreender esse paradoxo, eles propõem que se faça uma distinção entre regiões empíricas de fronteira e "fronteira" imaginada no interior nacional a partir de uma abordagem que considera a moral existente nessas distinções.

Segundo estes autores, as práticas que se dão nas fronteiras são moralmente plurais e frequentemente obscurecidas, enquanto a imaginação moral à distância é frequentemente baseada em uma ideia frequentemente simples e inequívoca sobre a fronteira. Porém, sugerem eles, a fronteira opera como um símbolo fortemente evocativo, altamente condensada e singular enquanto nas experiências de travessias as pessoas agem e pensam moralmente de maneiras diversas. Por isso, o simbolismo da fronteira existe também nas regiões de fronteira, contribuindo para dar forma às práticas locais. Vários tipos de relacionamentos surgem da prática nas fronteiras (comércio, trabalho/ emprego, educação, família, amizade etc.), os quais os autores propõem compreender da seguinte forma:

Being tied to other persons does and should impose a set of correlated obligations on their participants. While arguably all humans should have fundamental moral equivalence, in practical terms the persons to whom we owe moral equivalence are the ones with whom we have active relations. [...]. This is neither bounded by preexisting nation-state membership nor is it just a theoretical global equivalence between people who do not actually have relations. Seen as an emergent moral framework, relevant agents, duties, and moral goods begin to be defined (Heyman e Symons, 2012, p. 552). 
Nesse sentido, a fronteira enquanto símbolo transforma a área de fronteira em um ponto a partir do ou para o qual convergem diferentes atores sociais quando se trata de cultura ou de política cultural. Sendo, assim, pode-se perguntar: em que medida os ativistas culturais contribuem para a materialização da linha política que delimita os territórios nacionais? Como afirma Green (2010, p. 268), "border as line is not a literal line but a political line that equates to a conceptual and infinitesimally thin location". Com isso, estes agentes sociais tornam clara a linha que delimita o território de ambos os países, pois transformam em narrativas as práticas de cruzamento da fronteira, ajudando, assim, ao entendimento de sua existência no cotidiano das pessoas. Cabe aqui o argumento de Green, segundo o qual fronteiras

$[\ldots]$ are generated by people who are informed in their practices by notions of what constitutes border, and in historically changing conditions where these theories and the people who think them are not alone in the world, and so their efforts might or might not turn out in the way intended (Green, 2010, p. 261).

Por outro lado, a fronteira não é tão somente performatizada em linhas político-culturais, mas também faz parte da vida das pessoas de distintas maneiras. Para isso, cabe observar a sugestão de Velho (2008), de que seja revista a antropologia feita no Brasil (por brasileiros). Ele lembra a profunda relação da antropologia no Brasil com a construção da nação e acrescenta que essa antropologia também é neo-orientalista. Dessa maneira, pretende-se fugir da restrição e essencialização que implica a construção da nação (ou do bloco regional).

\section{"Fronteras culturales"}

A pesquisa cujos resultados são relatados a seguir começou no segundo semestre de 2014 e se estendeu até maio de 2015. Em Porto Alegre, o primeiro encontro foi com Ricardo Almeida, membro de equipe da Secretaria do Planejamento do governo Tarso Genro, com responsabilidades junto ao sistema informacional de participação popular na definição orçamento estadual. Nas atividades na fronteira, onde teve proeminência nas duas inicitivas aqui analisadas, ele se autointitula militante da cultura, sem vínculo direto com as ações do governo estadual em torno da cultura na fronteira entre Brasil e Uruguai. ${ }^{3}$

\footnotetext{
${ }^{3}$ Ele apresentou um relato sobre o movimento "fronteras culturares" no $2^{\mathrm{o}}$ Seminário Internacional Maioridade do Mercosul: Discutindo Fronteiras, entre os dias 12 a 14 de março de 2014, que ocorreu na Pontifícia Universidade Católica do Rio Grande do Sul (Pucrs). O relato foi publicado posteriormente em livro (ver Mallmann e Marques, 2015).
} 
Ricardo Almeida destacou o ano de 2009 como importante para a cultura de fronteira, pois Santana do Livramento foi declarada cidade símbolo da integração brasileira com os países membros do Mercosul. Como antecedentes que levaram à criação do Calendário da Integração Cultural Brasil-Uruguai, ele relatou a aprovação do projeto de pontos de cultura pelo Parlasul e o Sistema de Cultura do Ministério da Cultura do Brasil, que englobaria municípios, estados e a federação. O movimento Fronteras Culturales, do qual Ricardo participou, buscava a integração cultural por meio de ações que visavam o alinhamento de políticas entre união, estados e municípios, a elaboração de editais, a capacitação de agentes locais e a ênfase na singularidade das fronteiras nos acordos políticos.

Inicialmente supunha-se que Fronteras Culturales fosse um movimento organizado, um tipo de associação com regras de adesão e funcionamento sistemático. Isso foi uma idealização que pode ser debitada à ideia de movimento cultural como algo homogêneo, com objetivos claros e funções definidas para seus membros, associada mais às caraterísticas dos movimentos sociais tradicionais. No entanto, no encontro com Ricardo Almeida ficou claro o caráter não organizado no sentido tradicional de Fronteras Culturales, que de fato teve uma curta existência apesar de sua forte e organizada militância individual.

Ricardo Almeida era o único remanescente do movimento e articulava praticamente sozinho o Calendário da Integração Cultural Brasil-Uruguai no ano de 2014, o que pretendia deixar de fazê-lo esperando que o Comitê de Prefeitos e Intendentes de Cidades de Fronteira assumisse a tarefa. Foram estipulados três critérios para a inclusão e permanência de eventos no Calendário: 1) o evento não poderia ser apenas na fronteira, teria que ser de fronteira; 2) deveria gerar trabalho e renda para os trabalhadores da cultura e 3) deveria contar com a presença de uruguaios e brasileiros. A noção de fronteira associada à produção cultural que Ricardo estava mobilizando se referia a uma fronteira cultural e geograficamente localizada, geradora de trabalho e renda, economicamente relevante, e formada a partir da mistura das duas identidades nacionais legalmente constituídas, como são as cidadanias.

Cabe observar que Ricardo Almeida e outros militantes participaram de mobilizações que foram importantes para os acordos, políticas e eventos realizados pelo governo federal do Brasil, junto com seus homônimos no Cone Sul da América do Sul, que aconteceram nos anos de 2009 e 2010. No entanto, eles não estavam diretamente vinculados a um ministério ou outro órgão especificamente responsável por tais medidas, eram os autodenominados militantes da cultura de fronteira, vinculados a diferentes 
postos no executivo ou legislativo, em Brasília ou em outras cidades que participaram de importantes eventos e introduziram noções ligadas à cultura nesses acordos e políticas governamentais. Como o próprio Ricardo descreve, "um grupo de militantes culturais fronteiriços iniciou um processo de intensas mobilizações envolvendo ministérios, prefeitos, intendentes, alcaides, agentes e as organizações culturais dos dois países" (Almeida, 2015, p. 217).

Conforme Ricardo Almeida, pode-se observar uma trajetória de mobilizações que culminaram com a criação do movimento Fronteras Culturales. No ano de 2010 foram realizadas reuniões periódicas e seminários paralelamente à visita de autoridades, com destaque para as presenças na fronteira dos presidentes Luis Inácio Lula da Silva, do Brasil, e José Mujica, do Uruguai. Com a eleição de Dilma Rousseff para o governo federal em 2010 foram desarticuladas estruturas de governo nas quais aqueles militantes atuavam e o próprio movimento perdeu sua dinâmica. No entanto, também em 2010, Tarso Genro foi eleito para o governo do estado do Rio Grande do Sul e Ricardo passou a compor seu governo. A partir de então, ele atuou na fronteira como representante no Comitê Binacional de Intendentes e Prefeitos de Fronteira. Nesse contexto, foi o articulador do Calendário da Integração Cultural Brasil-Uruguai, que ocorreu em 2014. Em certo sentido, o Fronteras Culturales teve continuidade em um movimento conformado por componentes heterogêneos e objetivos em constante (re)definição.

$\mathrm{O}$ segundo encontro de pesquisa com Ricardo Almeida aconteceu em setembro de 2014, em uma reunião na qual foi entregue a Juca Ferreira, coordenador da área de cultura da campanha da candidata Dilma Rousseff à reeleição à presidência do Brasil, o Manifesto Cultural da Fronteira BrasilUruguai, assinado por dezenas de artistas, produtores, gestores públicos e militantes. Ferreira teve uma reunião em particular com cerca de vinte ou trinta pessoas para tratar da questão da fronteira. O Manifesto recuperava uma série de acontecimentos, desde a declaração de Santana do Livramento como cidade símbolo da integração brasileira com os países membros do Mercosul, em 2009, até o III Seminário da Integração Cultural que acontecera em junho de 2014 em Jaguarão e, além disso, fazia demandas diversas.

Menos de um ano depois, em maio de 2015, Juca Ferreira, já como Ministro da Cultura do Brasil, participou de uma reunião maior com aquele mesmo grupo e com outros que se juntaram a eles em Jaguarão, cidade que faz divisa com a uruguaia Rio Branco. Dessa vez foi acompanhado pela Ministra de Educação e Cultura do Uruguai, Maria Julia Muñoz, da presidente do Instituto do Patrimônio Histórico e Artístico Nacional do Brasil, Jurema Machado, entre outras autoridades. 
Esse dia foi o coroamento de uma série de esforços em torno da cultura na fronteira. Não apenas os esforços de Ricardo Almeida. Na ocasião compareceu um grupo significativo de pessoas que mantinham algo em comum que as ligava à cultura e à fronteira, por mais vago que pudesse ser esse compartilhamento, e foram reafirmadas algumas demandas presentes no manifesto entregue a Juca Ferreira antes de ele ser ministro. Na entrada do Auditório da Biblioteca Pública de Jaguarão, enquanto os ministros eram aguardados, circulavam pessoas como Enrique Mazzei, professor de sociologia da Universidad de la República (Udelar) de Cerro Largo, Uruguai, Adriana Dorffman, professora de geografia da Universidade Federal do Rio Grande do Sul (Ufrgs), assim como o próprio autor deste trabalho e tantos outros, preenchendo o espaço reservado à plateia de um ato público. Era possível estabelecer novos contatos, como por exemplo com os professores da Universidade Federal do Pampa (Unipampa) de Jaguarão, e com o presidente do Clube Negro de Jaguarão, que durante $o$ ato foi enfático ao falar sobre a importância do Clube para a população negra na cidade e sobre o preconceito que estavam sofrendo. Estava presente Rafael Andreazza, da Moviola Filmes de Pelotas, um dos realizadores do filme Linha Imaginária. Junto com ele também estava o realizador de cinema e organizador do Festival Internacional de Bagé, Zeca Brito. Fizeramse presentes também um grupo de responsáveis pelos Centros MEC, de cidades uruguaias relativamente próximas a Jaguarão, ${ }^{4}$ um autodenominado escritor de "Riveramento" - em alusão à proximidade entre as cidades Rivera, Uruguai, e Santana do Livramento, Brasil -, o então Secretário de Cultura de Santana do Livramento e professores e alunos do Instituto Federal Sul-rio-grandense (Ifsul) de Bagé participantes do Ponto de Cultura Pampa Sem Fronteiras.

$\mathrm{O}$ vínculo mais óbvio entre todas essas pessoas é a conformação de um bloco local perante a autoridade de Brasília para quem foram dirigidas demandas envolvendo leis, políticas e programas com efeitos locais. Para além dos diversos tipos de relacionamentos que se estabelecem na prática na fronteira (comércio, trabalho/emprego, educação, família, amizade etc.), se destacava o simbolismo dela propriamente dita. Desse modo emprestava-se ao símbolo uma força heterogênea, socialmente distribuída entre aqueles que lá estavam.

Conformava-se ali um agrupamento que colocava face a face um conjunto de pessoas do local e o então Ministro da Cultura do Brasil, além de sua congênere uruguaia, entre outras autoridades que figuravam como

\footnotetext{
${ }^{4}$ Os centros MEC são espaços educativos e culturais que descentralizam a ação do Ministério da Educação e Cultura do Uruguai.
} 
convidados. O Ministro ouviu pacientemente vários depoimentos. Todos eles expressavam a pulsação daquelas pessoas que provinham de diferentes cantos e manifestações político-culturais. De Jaguarão, ele ouviu profissionais das políticas culturais (um professor e uma aluna da Unipampa), uma filha de santo da religião afro e o presidente do clube negro, entre outros. De Bagé, ouviu representantes do Ponto de Cultura Pampa Sem Fronteiras. De Pelotas, ouviu Rafael Andreazza. De Porto Alegre, ouviu o presidente do Conselho Estadual de Cultura e o próprio Ricardo Almeida. Dava para perceber claramente que o Ministro estava inclinado a tornar-se um parceiro daquelas pessoas mobilizadas pela "cultura da fronteira".

\section{O Calendário}

A reunião com os Ministros em Jaguarão, em 2015, põe em tela a diversidade cultural da fronteira entre Brasil e Uruguai. Diversidade essa que era o foco de outra iniciativa na qual Ricardo Almeida esteve à frente e acontecera no ano anterior, o Calendário de Integração Cultural Brasil-Uruguai com o objetivo de promover "as ações de convivência, cooperação e intercâmbio artísticas e culturais que configuram um corredor cultural e turístico e revelam toda a singularidade e a diversidade da região da fronteira". ${ }^{5}$ A diversidade cultural foi destacada no Calendário como algo a ser reconhecido, vivenciado e divulgado para além do turismo de compras e da cultura 'pampeana'. Foram definidos critérios para os eventos serem incluídos no Calendário, dentre os quais no lado brasileiro ocorrerem em municípios na Faixa de Fronteira.

Cabe observar que a diversidade foi aliada a uma noção de integração cultural. Em alguma medida, essa noção levaria à institucionalização de diferentes formas de eventos considerados culturais. $\mathrm{O}$ teor dela, de acordo com a formulação de Ricardo Almeida, seria bastante objetivo no que diz respeito aos eventos. Cabe retomar os três critérios anteriormente mencionados: não basta acontecer na fronteira, tem que ser de fronteira; gerar trabalho e renda para os trabalhadores da cultura; e, por fim, contar com a presença de uruguaios e brasileiros. No entanto, tal objetividade parece depender de referências subjetivas, destacadamente aquelas provenientes de instâncias mais abrangentes como o Mercosul. Um indício disso foi a realização da reunião com os Ministros de Cultura de Brasil e Uruguai no Auditório da Biblioteca Pública no mesmo dia em que a Ponte Internacional Barão de Mauá foi declarada o primeiro patrimônio cultural do Mercosul. Ela conecta

\footnotetext{
${ }_{5}^{5}$ Disponível em <https://www.facebook.com/integracaoculturalbrasiluruguai/info?tab=page info $>$ (6 abr. 2015).
} 
Brasil e Uruguai por meio dos municípios de Jaguarão e Rio Branco. Por isso, foi possível depois da reunião que, os ministros e boa parte dos que estávamos lá presentes, nos deslocássemos até ela. Atravessamos a ponte até a aduana uruguaia, onde as autoridades máximas dos dois países presentes naquele momento descerraram uma faixa que cobria uma placa indicativa, simbolizando o reconhecimento oficial de um bem cultural do Mercosul.

Imagem 1. Ministro da Cultura do Brasil, Juca Ferreira, e Ministra de Educação e Cultura do Uruguai, Maria Julia Muñoz. 30 maio 2015

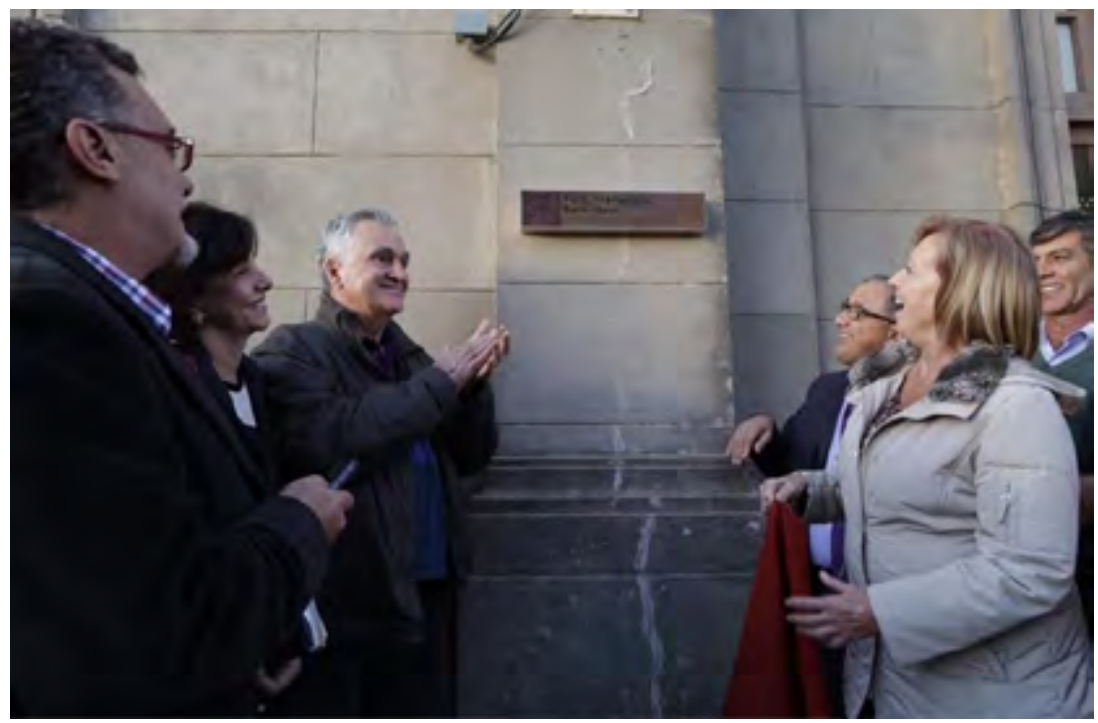

Fonte: Foto do autor.

Em Jaguarão, no dia anterior, foi possível conhecer a cidade, especialmente seus patrimônios históricos e cruzar a Ponte que seria oficialmente reconhecida como patrimônio cultural do Mercosul no dia seguinte. Em solo uruguaio, havia um pequeno pedestal com uma placa, escrita em espanhol e inglês, na qual se podia ler o significado histórico da ponte. Aquele pedestal acabava de ser colocado ali; a terra ao seu lado estava remexida e uma escora o apoiava, o que marcava a presença da comissão do patrimônio do Mercosul, que estava reunida em Jaguarão durante aquela semana.

Era essa a fronteira cultural da qual falara Ricardo Almeida em distintas ocasiões. Parecia um tanto óbvio demais, mas, enfim, essa era uma ideia que parecia plausível. Em Jaguarão, após a ponte, havia um galpão com a inscrição 
Centro de Comércio Informal ao lado de um contêiner com várias pinturas que não parecia estar lá por acaso. Isso também seria a fronteira cultural, era uma pergunta pertinente.

Imagem 2. "Centro de Comércio Informal" e contêiner ao lado da Ponte Internacional Barão de Mauá, em Jaguarão
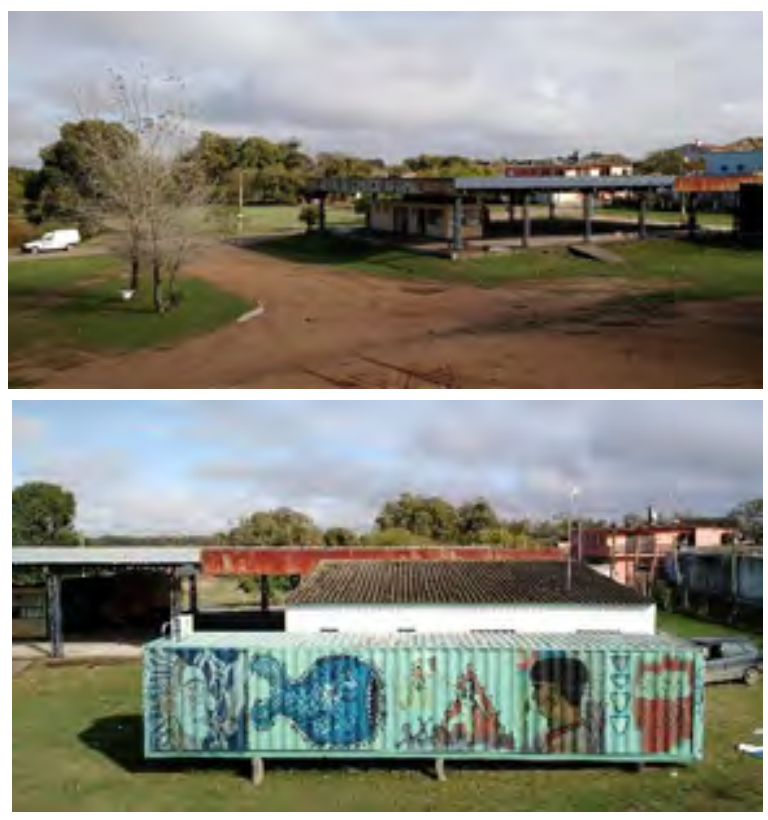

Fonte: Foto do autor.

Entre o Centro e o contêiner funciona o Sindicato dos Pescadores de Jaguarão, onde estava Olimar, pescador sindicalista e estudante de Produção Cultural da Unipampa. Segundo ele, o contêiner seria usado em uma pesquisa na Universidade, mas acabou sendo levado para lá onde teve um destino diferente. O Sindicato havia firmado um convênio com os Ministérios da Pesca e da Educação para instalar computadores com acesso à internet. Assim como Olimar se apresentou a este pesquisador, também lhe foi apresentada a pesquisa que ali este autor fazia. O título de um dos projetos de pesquisa mencionado, que começava com a palavra impactos, foi o mote para uma reflexão do pescador sindicalista sobre a vida na fronteira. Em linhas gerais, ele questionou sobre falar de impactos ou de convivência. Ele preferia falar de convivência. Segundo ele, esta não era uma escolha, exemplificando com 
o fato de os pescadores brasileiros e uruguaios se encontrarem no dia a dia, mas terem de respeitar as leis soberanas de cada país quando estão no rio. Para concluir disse: "o peixe não tem bandeira". Ali, ao lado da Ponte Internacional Barão de Mauá, primeiro patrimônio cultural do Mercosul, os argumentos de Heyman e Simons (2012) faziam sentido, com a distinção entre fronteira empírica e "fronteira" imaginada no interior nacional.

As reflexões de Olimar diante daquelas de Ricardo, entre tantas outras presenciadas em pesquisa de campo, provocaram reflexões que estão presentes neste trabalho. Naquele mesmo dia, à noite, em uma reunião do Conselho Municipal de Cultura com o fim preparar seus integrantes para o encontro com os Ministros, junto com Ricardo Almeida, estavam presentes o presidente do Conselho Estadual de Cultura Neidmar Charão e dois conselheiros, um deles o músico e radialista Demétrio Xavier. Ricardo abriu a reunião também falando de convivência. Dizia ele, "amanhã vem o Ministro e muita gente. Uma grande mobilização. Eles querem conhecer a nossa convivência na fronteira. Por isso é importante reforçar isso. Porque para quem vem de Brasília é tudo diferente. Para nós aqui é normal".

Os pescadores brasileiros e uruguaios que se encontram no dia a dia e compartilham as águas nas quais labutam fazem lembrar como em Santana do Livramento e Rivera, a linha que separa Brasil e Uruguai converte-se em um lugar que os transforma em "cá" e "lá" e "este lado" e "outro lado" (Sánchez, 2002). Conforme apontado anteriormente, essa convivência tem um valor nas mobilizações políticas dos ativistas culturais ao ser transformada em um conjunto diante de uma autoridade federal. Dessa maneira, pode-se dizer que a linha (ou mesmo a fronteira) foi reconvertida nesse processo.

Processo esse que pode ser compreendido como parte de uma dinâmica recente de relação entre "formas de produção cultural" e "modos de fazer política”. Essa dinâmica foi estudada por Irisarri $(2015$, p. 169, 171), que afirma tratar-se de

[...] uma nova configuração nas formas de produção cultural brasileira. [...] as mudanças nas concepções de cultura e as práticas que a envolvem indicam que atualmente ela é não só um espaço estético vinculado aos julgamentos do gosto, mas sim um âmbito de emprego, de desenvolvimento de uma carreira, de engajamento político e de criação de modos de vida. Estas concepções se afastam das ideias românticas da arte que se consolidaram na sociedade moderna, que associam a figura do artista à de um gênio, ao talento e à personalidade carismática, para aproximarem-se cada vez mais de concepções mundanas que se vinculam aos modos de ganhar a vida e de engajar-se com a política. 
Analisar os desdobramentos dessa nova configuração no contexto da fronteira entre Brasil e Uruguai envolve observar o fato de ser área limítrofe, onde a posição dos estados nacionais adquire caráter particular, ao mesmo tempo em que fornece certa matéria-prima para a produção cultural regional.

\section{Conclusões}

Com base neste trabalho, foi possível constatar que há um tipo de movimento cultural conformado por componentes heterogêneos e objetivos em constante (re)definição, que se expressou e, em alguns casos, continua se expressando por meio da organização de atos públicos, reuniões e manifestos que afirmam posições e concepções políticas que estariam mais próximas daqueles autodenominados militantes da cultura, mas que são também parte de uma dinâmica que se volta para a manutenção de festivais, exposições ou feiras que permitem a atividade daqueles autodenominados artistas na fronteira de Brasil e Uruguai.

Muitos ativistas culturais que estiveram envolvidos com o referido Calendário no ano de 2014, também o estiveram com outras mobilizações naquele ano e em 2015. Essas mobilizações ajudam a constituir o teor do que se entende por integração cultural. Para muitos ativistas, trata-se de eliminar os impedimentos para a livre circulação de artistas, escritores e outros agentes da cultura. Cabe aqui retomar a distinção teórica entre regiões de fronteira empíricas e "fronteira" imaginada no interior nacional (Heyman e Symons, 2012). Essa distinção é pertinente para discutir articulações políticas em torno da "cultura de fronteira". Isto é, a ideia de uma "cultura de fronteira" que surge nas iniciativas culturais na fronteira visa articular diferentes agentes em torno de ações voltadas ao processo de "borderization" (Grimson, 2012). Com isso, o simbolismo da fronteira reveste-se de uma força heterogênea, social e politicamente distribuída.

\section{Referências}

ALBUQUERQUE, José Lindomar Coelho. A dinâmica das fronteiras: deslocamento e circulação dos "brasiguaios" entre os limites nacionais. Horizontes Antropológicos, v. 31, p. 137-166, $2009<10.1590 / \mathrm{S} 0104-71832009000100006>$.

ALMEIDA, Ricardo. Calendário de Integração Cultural Brasil-Uruguai: uma experiência. In: Maria Izabel Mallmann; Teresa Cristina Schenider Marques (orgs.). Fronteiras e relações Brasil-Uruguai. Porto Alegre: Edipucrs, 2015. p. 215-236.

FAULHABER, Priscila. Fronteira na antropologia social: as diferentes faces de um problema. $B I B$, n. 51, p. 105-125, 2001. 
GREEN, Sarah. Performing border in the Aegean: on relocating political, economic and social relations. Journal of Cultural Economy. v. 3, n. 2, p. 261-278, 2010 $<10.1080 / 17530350.2010 .494376>$.

GRIMSON, Alejandro. Nations, nationalism and "borderization" in the Southern Cone. In: Thomas M. Wilson; Hastings Donnan (orgs.). Companion to border studies. Hoboken: Blackwell Publishing, 2012. p. 194-213 <10.1002/9781118255223.ch11>.

GRIMSON, Alejandro; VILA, Pablo. Forgotten border actors: the border reinforcers. a comparison between the U.S.-Mexico border and South American borders. Journal of Political Ecology, v. 9, n. 1, p. 69-88, $2002<10.2458 /$ v9i1.21635>.

HEYMAN, Josiah M.; SYMONS, John. Borders. In: Didier Fassin (org.). $A$ companion to moral anthropology. Chichester: John Wiley \& Sons, 2012. p. 540-557 $<10.1002 / 9781118290620 . c h 30>$.

IRISARRI, Victoria. Fora do eixo, dentro do mundo: política, mercado e vida cotidiana em um movimento brasileiro de produção cultural. Tese (Doutorado). Programa de Pós-Graduação em Antropologia Social Universidade Federal do Rio Grande do Sul. 2015.

MALlMANN, Maria Izabel; MARQUES, Teresa Cristina Schneider (orgs.). Fronteiras e relações Brasil-Uruguai. Porto Alegre: Edipucrs, 2015.

RABOSSI, Fernando. Como pensamos a Tríplice Fronteira? In: Lorenzo Macagno; Silvia Montenegro; Verónica Giménez Bélivau (orgs.). A Tríplice Fronteira: espaços nacionais e dinâmicas locais. Curitiba: Editora UFPR, 2011. p. 39-61.

SÁNCHEZ, Andrea Quadrelli. A fronteira inevitável: um estudo sobre as cidades de fronteira de Rivera (Uruguai) e Santana do Livramento (Brasil) a partir de uma perspectiva antropológica. Tese (Doutorado). Programa de Pós Graduação em Antropologia Social Universidade Federal do Rio Grande do Sul. 2002.

SPRANDEL, Marcia Anita. Brasileiros na fronteira com o Paraguai. Estudos Avançados. v. 20, n. 57, p. 137-156, $2006<10.1590 /$ S0103-40142006000200011>.

VELHO, Otávio. A antropologia e o Brasil, hoje. Revista Brasileira de Ciências Sociais, v, 23, n. 66, p. 5-9, 2008.

Recebido em: 10 dez. 2017

Aprovado em: 26 mar. 2018

Autor correspondente:

Felipe José Comunello

Ufrgs, Campus Litoral Norte

Rodovia RS 030, 11700, km 92 - Emboaba

95590-000 Tramandaí, RS, Brasil

FELIPE JOSÉ COMUNELLO < felipe.comunello@ufrgs.br>

Doutor em Antropologia Social pela Universidade Federal do Rio Grande do Sul (Porto Alegre, RS, Brasil), professor do Departamento Interdisciplinar do Campus Litoral Norte da Universidade Federal do Rio Grande do Sul em Tramandaí, RS, Brasil.

ORCID: https://orcid.org/0000-0002-1260-6056 